\title{
BIODEGRADAÇÃO DO BAGAÇO DE CANA-DE-AÇÚCAR POR MICRORGANISMOS RUMINAIS DE CAPRINOS E OVINOS
}

\author{
BIODEGRADATION OF SUGARCANE BAGASSE BY RUMINAL \\ MICROORGANISMS FROM SHEEP AND GOATS
}

\section{Gil Mario Ferreira GOMES ${ }^{1}$; Ângela Maria de VASCONCELOS ${ }^{2}$; Antonio Silvio do EGITO³; Jailton da Costa CARNEIRO ${ }^{4}$; Natália Lívia de Oliveira FONTELES ${ }^{5}$; Hévila Oliveira SALLES ${ }^{3}$}

1. Zootecnista, Mestre em Zootecnia, Universidade Estadual Vale do Acaraú - UVA, Sobral, CE, Brasil. gilmariofg@ yahoo.com.br; 2. Professora Adjunta, Departamento de Zootecnia - UVA, Sobral, CE, Brasil; 3. Pesquisador, Embrapa Caprinos e Ovinos, Sobral, CE, Brasil; 4. Pesquisador, Embrapa Gado de Leite, Juiz de Fora, MG, Brasil; 5. Graduanda em Zootecnia - UVA, Sobral, CE, Brasil.

RESUMO: No presente estudo objetivou-se avaliar a degradação do bagaço de cana-de-açúcar (BCA) integral (BIN) ou hidrolisado $(\mathrm{BH})$ pela microbiota ruminal de caprinos e ovinos de raças naturalizadas do Nordeste brasileiro e o potencial desses animais como fontes de microrganismos e/ou enzimas celulolíticas para degradação da fibra do BCA. Para hidrólise do BCA foi utilizada uma solução de $\mathrm{NaOH}$ a $50 \%, 30 \%$ na matéria seca (MS). Foram determinadas as concentrações de MS, proteína bruta (PB), cinzas (CZ), fibra detergente neutro (FDN), fibra detergente ácido (FDA), celulose (Cel), hemicelulose (Hcel) e lignina (Lig). A degradação in situ da FDN do BH foi determinada pela incubação ruminal em sacos de náilon nos tempos: 0, 6, 24 e 96 horas. A técnica de duas etapas preconizada por Tilley e Terry foi utilizada para determinar a digestibilidade in vitro da MS (DIVMS). Foi coletado conteúdo ruminal dos animais quatro horas após a infusão de $100 \mathrm{~g}$ de BIN via fístula ruminal para a separação de microrganismos associados às fases líquida e sólida, utilizando filtragem e extração com tampão fosfato de sódio $50 \mathrm{mM} \mathrm{e} \mathrm{pH} \mathrm{6,9,} \mathrm{respectivamente.} \mathrm{A} \mathrm{fração} \mathrm{sólida} \mathrm{foi}$ submetida ao cultivo in vitro com o substrato BIN, por 96 horas, para determinação da taxa de degradação da MS, FDN e atividade celulolítica. $\mathrm{O}$ pH foi determinado nos tempos de cultivo de 24, 48 e 96 horas. O pré-tratamento com NaOH aumentou a DIVMS $(\mathrm{P}<0,05)$. Não houve efeito de espécie sobre a DIVMS $(\mathrm{P}>0,05)$. A inclusão de $\mathrm{NaOH}$ aumentou a degradação in situ da FDN, apresentando os ovinos menor tempo de colonização (TC). Houve solubilização da Hcel, da Cel e da Lig no BCA pré-tratado com $\mathrm{NaOH}$. A atividade celulolítica se concentrou na fração sólida independente da espécie doadora do inóculo, sendo observado crescimento microbiano no cultivo in vitro do BIN a partir dessa fração. O $\mathrm{pH}$ aumentou com o tempo de cultivo in vitro. Microrganismos ruminais de caprinos e ovinos naturalizados do Nordeste brasileiro colonizaram e degradaram o $\mathrm{BIN}$ e $\mathrm{BH}$. O NaOH pode ser utilizado no pré-tratamento alcalino do BCA.

PALAVRAS-CHAVE: Enzimas celulolíticas, Hidróxido de sódio, Pequenos ruminantes, Resíduo.

\section{INTRODUÇÃO}

Com a demanda por fontes renováveis de combustíveis, a gasolina vem sendo paulatinamente substituída por etanol de cana-de-açúcar no Brasil. Dessa forma, a produção de cana-de-açúcar e, como consequência, do bagaço de cana-de-açúcar (BCA) tem aumentado nos últimos anos. O Brasil produziu na safra 2014/2015 o equivalente a 659 milhões de toneladas (CONAB, 2014), gerando $280 \mathrm{~kg}$ de BCA para cada tonelada processada. A não utilização pela indústria ou a má utilização desse resíduo resulta na contaminação ambiental, seja por seu acúmulo ou por sua queima, respectivamente. Sabe-se, no entanto, que o BCA é um material orgânico rico em celulose, um polímero de glicose, que pode vir a ser degradado até sua unidade básica e gerar álcool, conhecido como etanol de segunda geração, que atualmente não está sendo produzido a nível comercial.
Os principais estudos na biodegradação do BCA incluem a utilização de enzimas e compostos químicos (ácidos ou bases). Devido ao alto poder corrosivo dos ácidos, as investigações vêm sendo concentradas na utilização de enzimas e bases. Em relação ao uso de enzimas no Brasil, os estudos ainda são incipientes. No entanto, a grande biodiversidade brasileira se apresenta como um potencial celeiro de organismos que podem gerar enzimas com maior eficiência na degradação (LEWINSOHN; PRADO, 2005).

Fontes potenciais dessas enzimas são microrganismos que se desenvolvem em materiais lignocelulósicos da cana em decomposição ou em animais que possuem a capacidade de se alimentar e degradar a biomassa in natura, como os ruminantes domésticos. Dentre esses, os pequenos ruminantes adaptados a regiões com vegetação tipicamente lenhosas, como a Caatinga no Nordeste brasileiro, são vistos como fontes em potencial de microrganismos em seus estômagos capazes de 
sintetizar enzimas mais efetivas na degradação de alimentos fibrosos. Isto é corroborado por Cunha et al. (2011), onde, por meio de abordagens metagenômicas, observaram que cabras Moxotó tiveram significativa porcentagem de microrganismos ruminais ainda não conhecidos, compreendendo 16,8 e $34,3 \%$ dos microrganismos associados à fase líquida e sólida do conteúdo ruminal, respectivamente.

$\mathrm{O}$ pré-tratamento alcalino torna materiais lignocelulósicos mais susceptíveis ao ataque microbiano. Durante esse processo ocorre solubilização da hemicelulose e de parte da lignina (HENDRIKS; ZEEMAN, 2009). A lignina é um heteropolímero indigestível que pode se ligar a outros componentes da parede celular vegetal indisponibilizando-os além de atuar como barreira física dificultando a degradação dos substratos. Ribeiro et al. (2009) comprovaram estas hipóteses ao trabalharem com cana-de-açúcar tratada com hidróxido de sódio $(\mathrm{NaOH})$ ou óxido de cálcio $(\mathrm{CaO})$, ambos na concentração de $2,25 \%$ na matéria natural (MN). Neste estudo houve aumento da degradabilidade potencial da FDN, hemicelulose e celulose da cana-de-açúcar tratada com $\mathrm{CaO}$ ou $\mathrm{NaOH}$ de 49,25 e 91,21\%; 36,3 e 77,3\%; 43,92 e $85,98 \%$, respectivamente. $\mathrm{O}$ teor de lignina diminuiu de $6,1 \%$ no tratamento controle para $0,9 \%$ no tratamento com $2,5 \%$ de $\mathrm{NaOH}$.

Objetivando gerar informações sobre a degradação do BCA pela microbiota ruminal de caprinos e ovinos de raças naturalizadas do Nordeste do Brasil, no presente estudo avaliou-se a digestibilidade in vitro e in situ do BCA integral (BIN) e tratado com hidróxido de sódio (BCA hidrolisado - $\mathrm{BH}$ ), bem como a localização dos microrganismos/enzimas celulolíticas no conteúdo ruminal de animais alimentados com BCA e sua capacidade de crescimento in vitro.

\section{MATERIAL E MÉTODOS}

O trabalho foi conduzido na Embrapa Caprinos e Ovinos, localizada no Município de Sobral-CE, Região Nordeste do Brasil.

Para a hidrólise química, o BIN foi pulverizado com uma solução de hidróxido de sódio $(\mathrm{NaOH})$ a $50 \%$ na proporção de $80 \mathrm{~mL}$ para $100 \mathrm{~g}$ de BIN, em seguida, homogeneizado, e deixado em repouso por 24 horas em temperatura ambiente. Após esse período foi submetido à secagem em estufa de ventilação forçada a $65^{\circ} \mathrm{C}$ por 48 horas e, posteriormente, moído em peneira com malha de 5 $\mathrm{mm}$ ou de $1 \mathrm{~mm}$ para posterior incubação ruminal e digestibilidade in vitro, respectivamente.

Amostras de BIN e $\mathrm{BH}$ submetidas à secagem em estufa a $65^{\circ} \mathrm{C}$ com ventilação forçada por 48 horas foram moídas em peneira de $1 \mathrm{~mm}$ para análise química. Os métodos descritos em AOAC (1990) foram usados para determinar os teores de matéria seca (MS, método $\mathrm{n}^{\circ}$ 930.15), proteína bruta (PB, método $\left.n^{\circ} 984,13\right)$ e cinzas (CZ, método $\mathrm{n}^{\circ}$ 942,05), e a fibra detergente neutro (FDN), fibra detergente ácido (FDA) segundo Van Soest et al. (1991). Amilase e sulfito de sódio não foram usados na determinação da FDN. Ambos FDN e FDA não foram corrigidos para cinzas. A determinação da FDA foi realizada no resíduo detergente neutro e o resíduo em detergente ácido foi tratado com ácido sulfúrico $\left(\mathrm{H}_{2} \mathrm{SO}_{4}\right)$ para estimativa do teor de lignina (VAN SOEST et al., 1991). Os teores de celulose (Cel) e hemicelulose (Hcel) foram estimados por diferença.

Para o ensaio de degradação in situ foram utilizados três caprinos da raça Moxotó e três ovinos da raça Morada Nova, machos, fistulados no rúmen, com peso vivo médio de $21 \mathrm{~kg}$ e idade aproximada de 12 meses, mantidos em gaiolas metabólicas de madeira com bebedouro, comedouro e saleiro. As dietas foram formuladas para serem isoprotéicas e isofibrosas, e fornecidas em duas refeições, às oito horas e às $14 \mathrm{~h}$. A relação volumoso:concentrado foi 53,56:46,44. As fontes volumosas utilizadas foram o feno de capim Tifton 85 (Cynodon sp.) e o BCA seco ao sol (BIN). O concentrado foi formulado à base de milho e farelo de soja (Tabela 1).

Três gramas do $\mathrm{BH}$ e do BIN moídos a 5 $\mathrm{mm}$ foram incubados em sacos de náilon com dimensões $13 \times 5 \mathrm{~cm}$ e porosidade aproximada 60 $\mu \mathrm{m}$. Os sacos foram mantidos em estufa a $65^{\circ} \mathrm{C}$ por $24 \mathrm{~h}$, após colocados em dessecador por 30 minutos e pesados, obtendo-se o peso do saco vazio.

Os tempos de incubação foram 6, 24 e 96 horas (Sampaio, 1988). O tempo zero $\left(\mathrm{t}_{0}\right)$ foi obtido por meio da lavagem do material em água corrente. O número de réplicas foi de três para os tempos $6 \mathrm{e}$ 24 horas, quatro réplicas para 96 horas e 6 para o $t_{0}$. As réplicas referentes a cada tempo, exceto o $t_{0}$, foram colocadas no rúmen dentro de saco de náilon medindo 20x10 cm com uma corrente âncora de 10 $\mathrm{cm}$ e peso de $300 \mathrm{~g}$ para manter os sacos submersos no conteúdo ruminal. 
Tabela 1. Composição centesimal e química da dieta experimental expressos em porcentagem da MS (\%)

\begin{tabular}{lc}
\hline Alimentos & MS (\%) \\
\hline Bagaço de cana-de-açúcar & 23,56 \\
Feno Tifton 85 & 30,00 \\
Milho (grão) & 35,98 \\
Farelo de Soja & 9,93 \\
Fosfato Bicálcico & 0,521 \\
Calcário Calcítico & 0,015 \\
Total & 100,00 \\
\hline Composição em Nutrientes (Base MS) & \\
\hline Proteína bruta & 11,26 \\
Fibra em detergente neutro & 47,61 \\
Energia metabolizável (Mcal/kg) & 2,21 \\
Extrato etéreo & 2,33 \\
Cálcio & 0,33 \\
Fósforo & 0,30 \\
\hline
\end{tabular}

Utilizou-se incubação do tipo reversa, para que todos os sacos fossem retirados e lavados ao mesmo tempo, retirando, assim, o efeito de lavagem das fontes de variação. Após, os sacos foram imersos em água com gelo por 30 minutos para diminuir a atividade microbiana. Em seguida, foram lavados em água corrente até a mesma sair transparente. Posteriormente, foram colocados em estufa por 24 horas para secagem e pesados. O material residual foi moído em peneira com malha de $1 \mathrm{~mm}$ e colocado em frascos identificados para posterior análise de FDN (VAN SOEST et al., 1991).

Os dados observados do desaparecimento da FDN nos tempos 6, 24 e 96 horas foram usados para estimar os parâmetros de degradabilidade a partir da equação exponencial de Mehrez e Ørskov (1977) simplificada por Sampaio (1988). Os horários em que a taxa de degradação foi inferior ao $t_{0}$ não foram utilizados para obtenção da equação. Com os parâmetros estimados do modelo anterior, estimouse o tempo de colonização (TC) conforme preconizado por McDonald (1981). Para determinação da degradabilidade efetiva (DEf) utilizou-se a fórmula descrita por Ørskov e McDonald (1979). Os valores teóricos da taxa de passagem do BCA no rúmen, considerando animais em fase de mantença, foram: (k): 2, 6 e $8 \%$.

Para a avaliação da digestibilidade in vitro colheu-se inóculos ruminais de caprinos e ovinos, coletados diretamente do rúmen de animais fistulados e colocados em recipientes plásticos de $500 \mathrm{~mL}$. Após coados, foram transferidos para garrafas térmicas previamente aquecidas com água à temperatura aproximada de $39^{\circ} \mathrm{C}$ e transportadas, imediatamente, ao laboratório. Foi usado fluxo de $\mathrm{CO}_{2}$ por $10 \mathrm{~min}$, no recipiente com líquido ruminal.
Aproximadamente $0,5 \mathrm{~g}$ de $\mathrm{BIN}$ e $\mathrm{BH}$, secos e moídos $(1 \mathrm{~mm})$ foram colocados nos tubos com fluido ruminal diluído 1:4, líquido ruminal:saliva artificial, respectivamente. Seguiu-se a técnica de duas etapas descrita por Tilley e Terry (1963).

Para verificar a localização dos microrganismos celulolíticos e respectiva atividade enzimática no rúmen, dois caprinos da raça Moxotó e dois ovinos da raça Morada Nova, machos, fistulados no rúmen, peso vivo médio de $35 \mathrm{~kg}$ e idade aproximada de 24 meses, receberam por um período de 21 dias, $50 \mathrm{~g}$ de BIN (partículas de 5 $\mathrm{mm}$ ) fornecidas juntamente com a dieta total no cocho, duas vezes ao dia (total $100 \mathrm{~g} / \mathrm{dia}$ ). No dia da coleta do conteúdo ruminal, com o animal em jejum, foi retirada uma alíquota de conteúdo ruminal e, em seguida, administrados via fístula, $100 \mathrm{~g}$ de BIN (partículas de $5 \mathrm{~mm}$ ), homogeneizados ao conteúdo ruminal presente e logo então fechada a fístula. Quatro horas após, foi realizada nova coleta do conteúdo ruminal, em garrafas térmicas previamente aquecidas $\left(39^{\circ} \mathrm{C}\right)$, estimado o volume do conteúdo recuperado e separada a fração líquida da porção sólida, por filtragem em pano de trama fina. Foi usado fluxo de $\mathrm{CO}_{2}$ nos recipientes contendo as frações do material ruminal. O material sólido retido no pano foi transferido para um becker e acrescido de tampão fosfato de sódio $50 \mathrm{mM}$, pH 6,9, até atingir o volume original do conteúdo ruminal e, sob fluxo de $\mathrm{CO}_{2}$, agitado com um bastão por, aproximadamente, $15 \mathrm{~min}$, seguindo nova filtragem. O filtrado obtido recebeu a denominação de fração sólida.

Amostras da fração sólida de conteúdo ruminal de caprinos e ovinos foram submetidas ao cultivo in vitro com o substrato BIN, por 96 horas, em ambiente anaeróbio, a $39^{\circ} \mathrm{C}$, ou seja, $0,5 \mathrm{~g}$ de 
BIN seco e moído $(1 \mathrm{~mm})$ foi adicionado a tubos contento $10 \mathrm{~mL}$ de inóculo de fração sólida e $40 \mathrm{~mL}$ de saliva artificial, a mesma saliva artificial preconizada pela técnica de Tilley e Terry (1963). Com potenciômetro digital avaliou-se o $\mathrm{pH}$ ao longo do cultivo (24, 48 e 96 horas). Determinou-se a concentração de proteína ao longo do cultivo nesses mesmos tempos. Após as 96 horas de cultivo in vitro foram determinadas nas amostras a taxa de degradação da MS e a da FDN. A atividade celulolítica foi determinada a zero hora em amostras de conteúdo ruminal provenientes tanto da fração líquida como da fração sólida, assim como nas amostras cultivadas in vitro por 96 horas com inóculo proveniente da fração sólida.

Para determinação de proteína das frações foi seguida a metodologia de Bradford (1976), utilizando a albumina sérica bovina como padrão, e para determinação da atividade celulolítica nas frações e no cultivo in vitro utilizou-se a técnica de difusão em gel de ágar (SALLES et al., 2010).

O delineamento experimental adotado para o ensaio in situ foi o em blocos ao acaso com parcelas subdivididas, sendo os animais os blocos, os tempos de incubação as parcelas e o alimento a subparcela. Para a estimativa dos parâmetros de degradação analisou-se os dados por espécie, processando-os pelo método interativo e utilizandose o procedimento NLIN do pacote estatístico SAS (2009) para modelos não-lineares.
No ensaio de digestibilidade e cultivo in vitro, bem como de atividade celulolítica utilizou-se o delineamento inteiramente casualizado. Os dados foram analisados pelo teste $t$ de Student ao nível de significância de 5\%.

\section{RESULTADOS E DISCUSSÃO}

$\mathrm{O}$ pré-tratamento do $\mathrm{BIN}$ com $\mathrm{NaOH}$ aumentou a digestibilidade in vitro da matéria seca (DIVMS) (Tabela 2). Como pode ser observado, houve aumento de $73,42 \%$ na DIVMS quando este resíduo lignocelulósico foi pré-tratado com $\mathrm{NaOH}$ na proporção de $30 \%$ da MS $(\mathrm{P}<0,05)$. Pires et al. (2006) testaram doses crescentes de $\mathrm{NaOH}$ sobre o BCA $(0 ; 2,5 ; 5$ e $7,5 \%$ base da MS) e observaram efeito quadrático crescente das doses de $\mathrm{NaOH}$ sobre a DIVMS. Segundo esses autores, a solubilização parcial da hemicelulose é um dos fatores que contribui para esse efeito, facilitando, portanto, a ação microbiana. Isto foi constatado no presente estudo onde a hemicelulose foi solubilizada com o pré-tratamento do BCA (Tabela 3). A solubilização parcial da lignina (Tabela 3) também pode explicar o aumento da DIVMS do $\mathrm{BH}$, uma vez que esta fração consiste numa barreira física para a degradação dos carboidratos estruturais por microrganismos.

Tabela 2. Digestibilidade in vitro da matéria seca (DIVMS) do bagaço de cana integral (BIN) e hidrolisado $(\mathrm{BH})$

\begin{tabular}{lcc}
\hline Espécie & BIN & BH \\
\hline Caprina & $39,84 \pm 2,30^{\mathrm{a}}$ & $70,87 \pm 1.78^{\mathrm{b}}$ \\
Ovina & $45,33 \pm 0,88^{\mathrm{a}}$ & $76,86 \pm 3.10^{\mathrm{b}}$ \\
\hline Média & $42,59 \pm 1.65^{\mathrm{a}}$ & $73,86 \pm 2,08^{\mathrm{b}}$ \\
\hline
\end{tabular}

${ }^{a, b}$ Letras diferentes na mesma linha diferem pelo teste $t$ de Student $(\mathrm{P}<0,05)$.

A composição química do BIN e do BH está sendo apresentada na Tabela 3, onde pode ser observado que houve alteração com o tratamento com $\mathrm{NaOH}$. $\mathrm{O} \mathrm{NaOH}$ atuou principalmente na solubilização da Hemicelulose (Hcel), com uma redução de 40,96\% na base da MS e, retirando o efeito das cinzas (CZ), uma redução de $37,39 \%$ na base matéria orgânica (MO). Efeito semelhante foi observado por Sun et al. (2004), onde constataram que tratamento do bagaço de cana com $10 \%$ de $\mathrm{KOH}$ ou $10 \%$ de $\mathrm{NaOH}$ liberou 92,5 e $95,5 \%$ da hemicelulose, respectivamente. Segundo esses autores a localização mais externa da hemicelulose facilita sua solubilização em relação à celulose que se encontra no interior da fração fibrosa. Outro aspecto é que com a remoção da hemicelulose e da lignina, as cadeias de celulose tornam-se mais alinhadas aumentando o grau de cristalinidade, o que aumenta a resistência ao tratamento alcalino (Van Soest, 1994). Isso, provavelmente, explica a alta recuperação da celulose no presente estudo que foi de $86,06 \%$ na MS e $85,08 \%$ na MO. A lignina, assim como a hemicelulose, apresentou alta solubilização, sendo observado $45 \%$ na MS e $24,73 \%$ na MO. Estas informações são necessárias para o entendimento do processo de isolamento da celulose como etapa para sua degradação até glicose e gerar biocombustíveis. Neste contexto, vários estudos apontam o $\mathrm{NaOH}$ como fonte potencial em deslignificar compostos da parede celular de células vegetais (TARKOV; FEIST, 
1969; CHAUDHRY, 1998b; PEREIRA FILHO et al., 2003).

Vários trabalhos mostram efeito semelhante do $\mathrm{NaOH}$ sobre a digestibilidade da MS em diferentes materiais fibrosos. Chaudhry (1998a) observou aumento de $21,72 \%$ na degradação ruminal da MS da palha de trigo tratada com $8 \%$ de $\mathrm{NaOH}$ na MS. A DIVMS do feno de jurema-preta tratado com $8 \%$ de $\mathrm{NaOH}$ aumentou de 30,43 para $45,54 \%$ em relação ao tratamento controle $(0 \%$ de $\mathrm{NaOH}$ ), aumento de $33,18 \%$ (PEREIRA FILHO et al., 2003). Estes resultados corroboram a maior eficiência do $\mathrm{NaOH}$ na deslignificação de resíduos fibrosos. No presente estudo, os valores de DIVMS foram superiores aos destes trabalhos em função da maior concentração de $\mathrm{NaOH}$ utilizada, $30 \%$ na MS. Vale ressaltar que esta quantidade não é recomendada para fins nutricionais, devido o poder causticante do hidróxido de sódio, mas em função de ter aumentado a digestibilidade in vitro da MS do BCA, pode-se inferir que o $\mathrm{NaOH}$ não comprometeu os processos de adesão e colonização da partícula pelas bactérias ruminais na fase de latência.
Não houve efeito de espécie sobre a DIVMS do $\mathrm{BIN}$ e $\mathrm{BH}(\mathrm{P}>0,05)$. A comparação entre espécie pode ser observada na Tabela 4 , onde é apresentada a cinética de degradação ruminal pela técnica in situ da FDN do BIN e BH. Na Figura 1 são apresentadas as curvas de degradação ruminal da FDN do BIN e BH em caprinos e ovinos.

$\mathrm{O}$ desaparecimento da FDN do $\mathrm{BH}$ foi superior ao do BIN, principalmente após 20 horas de incubação, apresentando pico de degradação em 48 horas (Figura 1). Este efeito foi semelhante ao padrão de desaparecimento da FDN da palha de trigo tratada com $\mathrm{NaOH}$ (8\% na MS) em ovinos observado por Chaudry (2000), que apresentou pico de degradação ruminal às 48 horas. Estas observações mostram que o pré-tratamento do BCA com $\mathrm{NaOH}$ proporciona maior exposição da celulose à ação enzimática de microrganismos ruminais. Chen et al. (2008) observaram maior atividade de carboximetilcelulase, avicelase e xilanase em palha de arroz tratada com $\mathrm{NaOH}$ (4,5\% na base MS).

Tabela 3. Composição químico-bromatológica do bagaço de cana-de-açúcar integral (BIN) e hidrolisado (BH) na base de matéria seca (MS) e na base de matéria orgânica (MO)

\begin{tabular}{lcccc}
\hline Componente & BIN & BH & BIN & BH \\
\hline Matéria Seca & 95,97 & 90,55 & - & - \\
Matéria Orgânica & - & - & 71,99 & 98,33 \\
\hline & \multicolumn{2}{c}{$(\% \mathrm{MS})$} & \multicolumn{2}{c}{$(\% \mathrm{MO})$} \\
\hline Proteína Bruta & 1,81 & 2,23 & 1,84 & 3,10 \\
Fibra Detergente Neutro & 64,95 & 47,70 & 66,06 & 66,26 \\
Fibra Detergente Ácido & 43,44 & 35,00 & 44,18 & 48,61 \\
Celulose & 36,15 & 31,11 & 36,77 & 43,22 \\
Hemicelulose & 21,51 & 12,70 & 22,41 & 14,03 \\
Lignina & 7,20 & 3,96 & 7,32 & 5,51 \\
Cinzas & 1,67 & 28,01 & - & - \\
Cinzas $_{(\mathrm{FDN})}$ & 0,70 & 0,42 & - & - \\
\hline
\end{tabular}

Tabela 4. Parâmetros de degradação ruminal e degradabilidade efetiva (DEf) para as taxas de passagem 2, $6 \mathrm{e}$ $8 \% / \mathrm{h}$ da fibra em detergente neutro (FDN) do bagaço de cana-de-açúcar integral (BIN) e hidrolisado (BH) em caprinos e ovinos.

\begin{tabular}{|c|c|c|c|c|}
\hline \multirow{3}{*}{ Variáveis } & \multicolumn{2}{|c|}{ Espécie } & \multicolumn{2}{|c|}{ Espécie } \\
\hline & Caprina & Ovina & Caprina & Ovina \\
\hline & \multicolumn{2}{|c|}{ BIN } & \multicolumn{2}{|c|}{$\mathrm{BH}$} \\
\hline $\mathrm{A}(\%)^{1}$ & 33,82 & 31,36 & 72,57 & 73,8 \\
\hline $\mathrm{c}(\% / \mathrm{h})^{1}$ & 1,6 & 2,7 & 4,77 & 4,30 \\
\hline S (\%) & 7,41 & 7,41 & 4,95 & 4,95 \\
\hline TC (horas) ${ }^{1}$ & $-0,49$ & 1,69 & 1.64 & 0.88 \\
\hline $\operatorname{DEf}(2 \% / h)^{2}$ & 19,05 & 22,63 & 62,01 & 56,20 \\
\hline
\end{tabular}




$\begin{array}{lllll}\text { DEf }(6 \% / h)^{2} & 12,95 & 15,62 & 40,82 & 36,30 \\ \operatorname{DEf}(8 \% / h)^{2} & 11,80 & 14,08 & 35,20 & 31,20\end{array}$

${ }^{1}$ Parâmetros da equação para estimar a degradação (d) em um determinado tempo (t): Deg = A - B exp(-c*t) (Sampaio, 1988). Potencial máximo de degradação (A), taxa de degradação da fração "B" (c), frações solúveis (S) e tempo de colonização (TC) oriundo da equação $\mathrm{TC}=-(1 / \mathrm{c}) *\left(\log _{\mathrm{n}}((\mathrm{A}-\mathrm{S}) / \mathrm{B})\right) \cdot{ }^{2} \mathrm{DEf}=\mathrm{a}+\left(\left(\mathrm{B}^{*} \mathrm{c}\right) /(\mathrm{c}+\mathrm{k})\right)$.

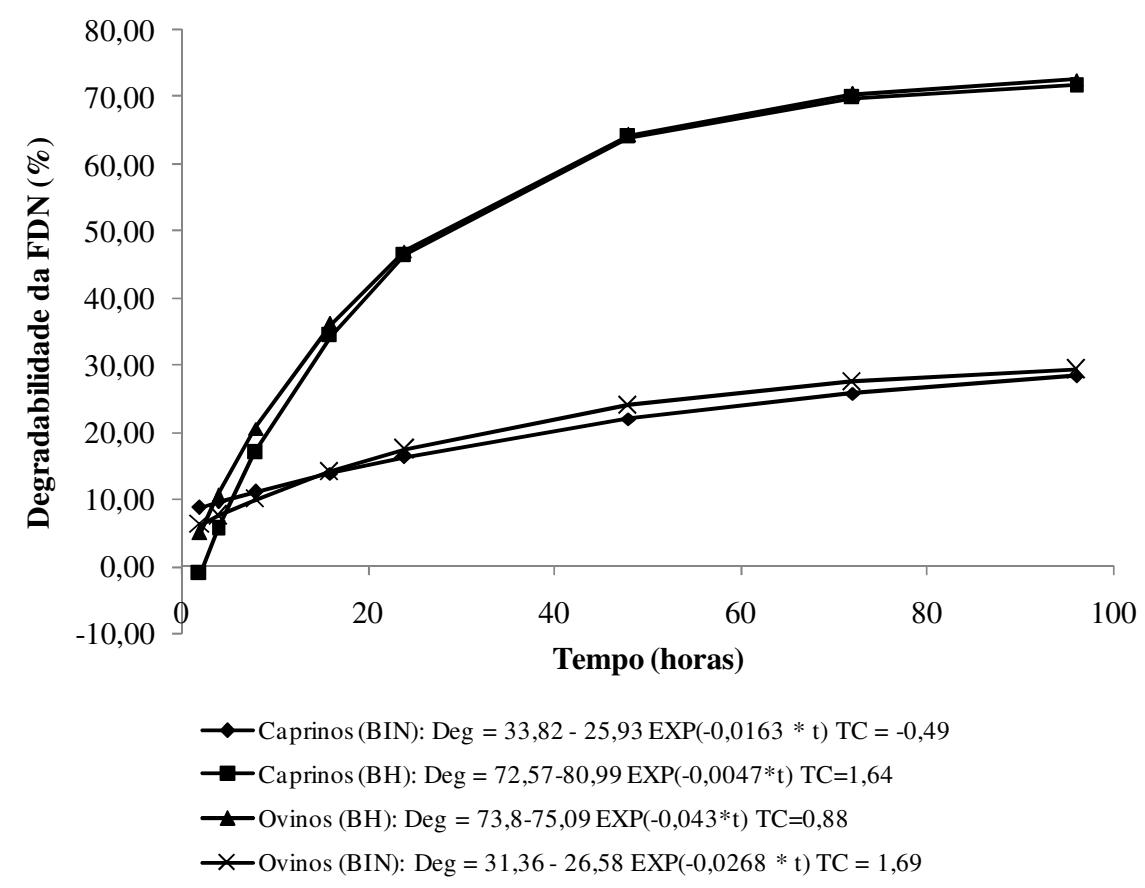

Figura 1. Degradabilidade ruminal da fibra em detergente neutro (FDN) do bagaço de cana-de-açúcar integral (BIN) e hidrolisado (BH) em caprinos e ovinos. Onde: Deg: degradabilidade (\%); t: tempo de incubação (h): e TC: tempo de colonização. exp(c*t) (Sampaio, 1988).

A maior extensão da degradação ruminal da FDN do BH (Figura 1) foi devido ao aumento do potencial de degradação (A), da taxa de degradação (c) e da degradabilidade efetiva (DEf) quando o bagaço de cana foi pré-tratado com $\mathrm{NaOH}$. A magnitude desses valores foi bem expressiva sendo observado aumento de 114,58 e $135,33 \%$ para $\mathbf{A}$ e de 198,12 e $59,26 \%$ para c em caprinos e ovinos, respectivamente.

$\mathrm{O}$ aumento do valor de $\mathbf{A}$ do bagaço de cana tratado com $\mathrm{NaOH}$ indica maior disponibilidade de nutrientes aos microrganismos ruminais, pois este parâmetro representa o limite máximo de degradação. De modo geral, o $\mathrm{NaOH}$ atua na hidrólise das ligações éster entre lignina e carboidratos complexos (VAN SOEST, 1994; MOORE e JUNG, 2001). A alta susceptibilidade de resíduos lignocelulósicos ao tratamento com $\mathrm{NaOH}$ é devido a maior proporção de ligações do tipo éster (VAN SOEST, 1994). De fato, a remoção da lignina é um ponto chave para o aproveitamento de resíduos lignocelulósicos, uma vez que, é um composto polifenólico indigestível derivado dos aminoácidos aromáticos fenilalanina e tirosina (MOORE; JUNG, 2001; LEHNINGER, 2011), atuando, portanto, como uma barreira física impedindo o aproveitamento da celulose (Reyes et al., 1998). O potencial de deslignificação do $\mathrm{NaOH}$ é confirmado no presente estudo (Tabela 4).

Os valores de c do $\mathrm{BH}$ foram próximos entre as espécies, o que explica a sobreposição das curvas de degradação ruminal entre as espécies a partir de 24 horas de incubação ruminal (Figura 1). Chaudhry (2000) observou taxa de degradação da FDN da palha de trigo tratada com $\mathrm{NaOH}(8 \%$ na MS) em ovinos semelhante ao deste estudo, $4,8 \% / \mathrm{h}$, que por sua vez, foi significativamente maior ao tratamento controle $(0 \%$ de $\mathrm{NaOH})$, com $1,2 \% / \mathrm{h}$. As taxas de digestão e passagem determinam a DEf. Este parâmetro é de relevância nutricional porque determina o grau de exploração do potencial de degradação do alimento. Os ovinos exploram mais o A do BIN que o do BH. Por outro lado, os microrganismos ruminais de ovinos tiveram menor 
tempo de colonização (TC). O menor TC em ovinos parece ter sido responsável pela maior degradação ruminal até 16 horas em ovinos (Figura 1), ou seja, provavelmente houve efeito compensatório para sobreposição das curvas de degradação da FDN do BH. Segundo Miron et al. (2001), tempo de colonização ou lag time representa o tempo necessário para as bactérias colonizarem o substrato para posterior fracionamento. No presente estudo, portanto, houve crescimento microbiano mais acelerado na espécie ovina. Neste contexto, ressaltase a necessidade de mais estudos para seleção de microrganismos eficientes em degradar celulose tendo como fontes ovinos e caprinos naturalizados de zonas semiáridas.

Os dados de digestão in vitro e degradação in situ nesta pesquisa suportam o potencial de caprinos e ovinos naturalizados do Nordeste brasileiro em degradar BIN e $\mathrm{BH}$, no entanto, a localização de microrganismos celulolíticos no rúmen desses animais é necessária para sua seleção. Segundo Chen et al., 2008 os microrganismos aderidos às partículas de alimento no conteúdo ruminal são os principais responsáveis pela degradação de carboidratos estruturais. Isto é corroborado no presente estudo, uma vez que, a atividade celulolítica sobre a carboximetilcelulose após 96 horas de cultivo in vitro se concentrou na porção sólida do conteúdo ruminal, independente da espécie doadora do inóculo (Figura 2). Diante desse resultado, os testes subseqüentes de cultivo in vitro até 96 horas foram usados apenas frações sólidas de caprinos e ovinos (Figura 3 e 4).

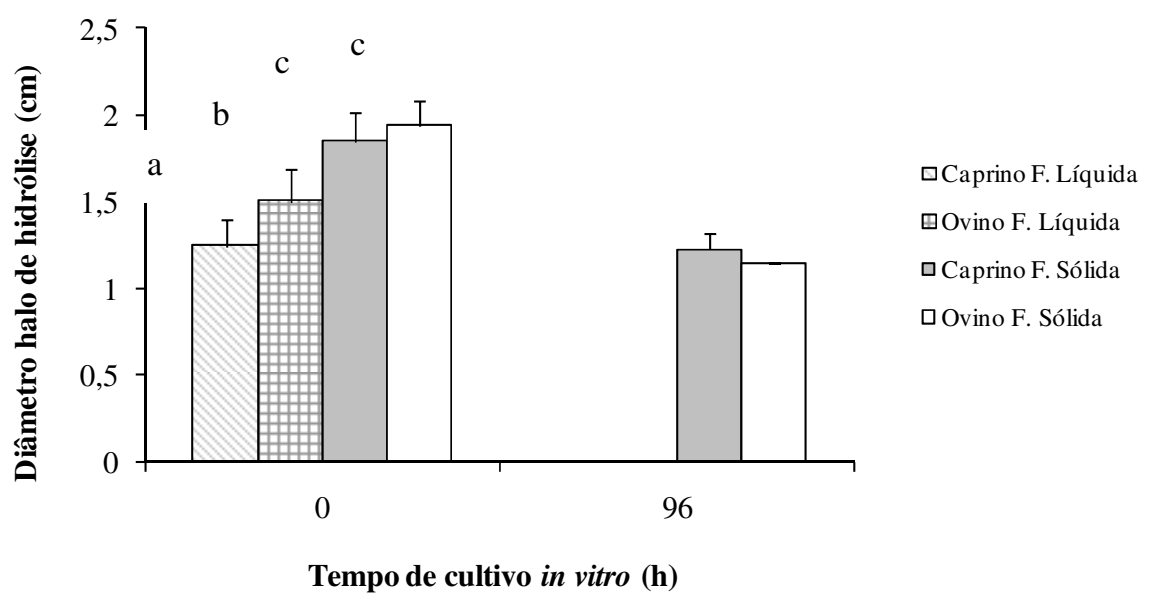

Figura 2. Diâmetro do halo de hidrólise $(\mathrm{cm})$ da carboximetilcelulose a $1 \%$ em placa de ágar a $2 \%$ pelas frações líquidas e sólidas antes do cultivo e pelas frações sólidas após $96 \mathrm{~h}$ de cultivo in vitro, para as duas espécies estudadas. Letras diferentes indicam diferença significativa $(\mathrm{P}<0,05$, teste $t$ de Student). 




Figura 3. Efeito do tempo de cultivo in vitro de inóculos das frações sólidas do rúmen de caprinos e ovinos sobre o $\mathrm{pH}$. Letras diferentes diferem entre si pelo teste $\mathrm{t}$ de Student $(\mathrm{P}<0,05)$.

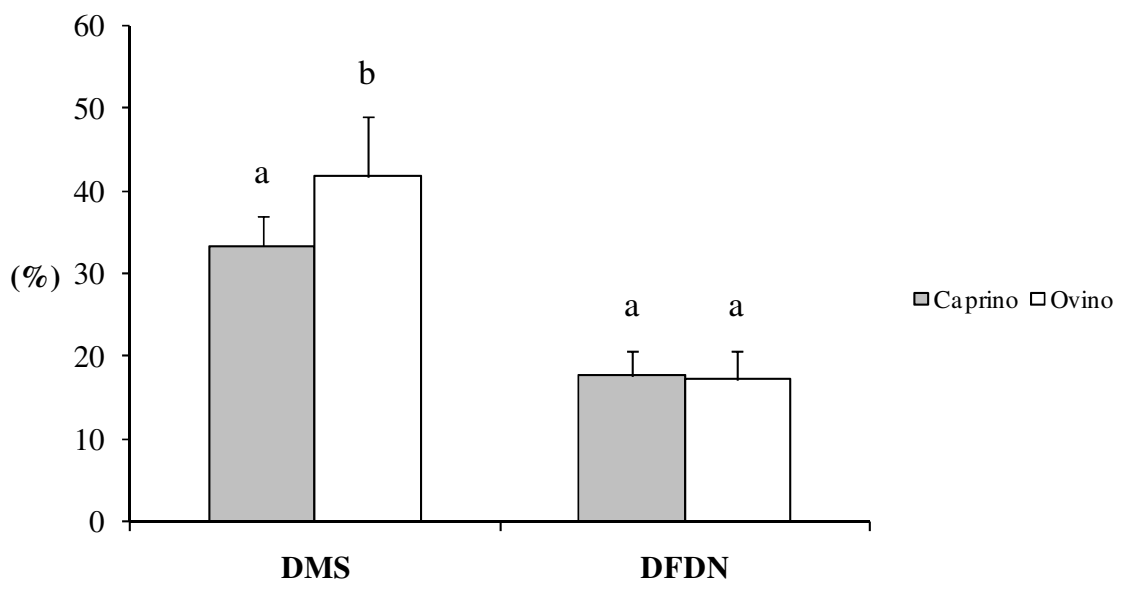

Figura 4. Efeito do tempo de cultivo in vitro com inóculos das frações sólidas do rúmen de caprinos e ovinos sobre a degradação da matéria seca (DMS) e da fibra em detergente neutro (DFDN) do bagaço de cana-de-açúcar integral. Letras diferentes diferem entre si pelo teste t de Student $(\mathrm{P}<0,05)$.

Foi verificada a viabilidade do cultivo in vitro dos microrganismos presentes em $10 \mathrm{~mL}$ de inóculo das frações sólidas de caprinos e ovinos, contendo 66,10 e $57,21 \mu \mathrm{g}$ de proteína/mL, respectivamente.

Na Figura 3 é apresentada a dinâmica de alteração do $\mathrm{pH}$ ao longo do tempo de cultivo in vitro. Observa-se uma mudança crescente e significativa no $\mathrm{pH}(\mathrm{P}<0,05$, teste $\mathrm{t})$ ao longo do tempo para todas as amostras analisadas. $\mathrm{O} \mathrm{pH}$ ideal para atividade microbiana no rúmen é de $6,7 \pm 0,5$, abaixo de 6,2 afeta negativamente a degradação da parede celular (VAN SOEST, 1994). No presente estudo, os dados de $\mathrm{pH}$ ficaram acima do mínimo preconizado para que haja adequada degradação da fibra, no entanto, existem evidências de que algumas bactérias celulolíticas diminuem drasticamente seu potencial de adesão ao substrato fibroso em $\mathrm{pH}$ acima de 7,5 (MIRON et al 2001). O tempo de cultivo in vitro de 96 horas apresentou os maiores valores de $\mathrm{pH}$, acima dos valores considerados ótimos para adesão e degradação microbiana.

Não foi detectada proteína nas amostras obtidas às $24 \mathrm{~h}$ e $48 \mathrm{~h}$ do início do cultivo in vitro, apenas às $96 \mathrm{~h}$ foi detectado 50,58 e 86,94 $\mu \mathrm{g}$ de proteína/mL para os inóculos de caprinos e ovinos, respectivamente. Os resultados sugerem a síntese de proteína in vitro a partir dos inóculos submetidos a cultivo, ou seja, houve crescimento microbiano ao longo do tempo de cultivo anaeróbio. Esse crescimento de microrganismos celulolíticos in vitro está, também, respaldado pela degradação da matéria seca e da FDN do BIN utilizado como substrato (Figura 4). Nota-se que a degradação in 
vitro da matéria seca do BIN foi maior utilizando inóculo ruminal de ovinos em relação ao de caprinos $(\mathrm{P}<0,05)$. Por outro lado, a degradação da FDN do BIN foi semelhante entre os inóculos ruminais de caprinos e ovinos, corroborando com a degradabilidade da FDN pela técnica in situ (Figura $1)$.

\section{CONCLUSÕES}

Microrganismos ruminais de Caprinos e ovinos naturalizados do Nordeste brasileiro colonizaram e degradaram o bagaço de cana-deaçúcar integral e hidrolisado, mostrando-se como fontes de microrganismos celulolíticos com potencial em degradar este resíduo lignocelulósico. A seleção desses microrganismos deve ser feita na parte sólida do conteúdo ruminal.

O hidróxido de sódio foi eficiente em deslignificar o BCA, portanto, pode ser utilizado como pré-tratamento alcalino para aumentar a eficiência de degradação do bagaço de cana-deaçúcar integral por microrganismos celulolíticos de caprinos e ovinos naturalizados do Nordeste brasileiro.

O mecanismo de ação dos microrganismos ruminais de caprinos e ovinos naturalizados do Nordeste brasileiro sobre o bagaço de cana-deaçúcar deslignificado deve ser investigado objetivando identificar enzimas ou grupo de enzimas eficazes em degradar o $\mathrm{BH}$ até glicose para serem utilizadas na produção de biocombustíveis.

\section{AGRADECIMENTOS}

Os autores agradecem ao Plano de Aceleração do Crescimento da Embrapa (PAC Embrapa) pelo financiamento do trabalho (projeto número 03.08.04.004.00).

\begin{abstract}
The purpose of this study was to evaluate the biodegradation of sugar cane bagasse (SCB), whole (WB) or hydrolyzed (HB) by ruminal microorganisms from Brazilian naturalized goat and sheep breeds, and the animals' potential as a source of microorganisms and/or cellulolytic enzymes for the biodegradation of SCB fiber. SCB hydrolysis was performed using $50 \%$ sodium hydroxide solution on $30 \%$ of dry matter (DM). The concentrations of DM, crude protein $(\mathrm{CP})$, ether extract (EE), ash, neutral detergent fiber (NDF), acid detergent fiber (ADF), cellulose (Cel), hemicellulose (Hcel) and lignin (Lig) were determined in the WB and HB. For the in situ biodegradation of NDF, the HB was placed in nylon bags and incubated in rumen for 0, 6, 24 and 96 hours. The two-step technique recommended by Tilley and Terry was used to determine the in vitro digestibility of DM (IVDDM). Four hours after infusion of WB (100 g) through the ruminal fistula, the rumen content was collected from the animals and the microorganisms associated with the liquid and solid phases were separated, the former by filtration and the latter by extraction with 50 mM sodium phosphate buffer, $\mathrm{pH}$ 6.9. The solid fraction was subjected to in vitro culture with WB substrate for 96 hours to determine the biodegradation rate of DM, NDF and cellulolytic activity. The pH was measured after culture times of 24, 48 and 96 hours. Pretreatment with $\mathrm{NaOH}$ increased the IVDDM $(\mathrm{P}<0.05)$. No species effect on the IVDDM was detected $(\mathrm{P}>0.05)$. The addition of $\mathrm{NaOH}$ increased the in situ biodegradation rate of NDF, with sheep showing a lower lag time (LT). There was a solubilization of $\mathrm{Hcel}, \mathrm{Cel}$ and Lig in SCB pretreated with $\mathrm{NaOH}$. Cellulolytic activity was higher in the solid phase, irrespective of the inoculum source, and microbial growth was observed in in vitro cultures using microorganisms from the solid phase and $\mathrm{WB}$ as substrate. The $\mathrm{pH}$ of the in vitro culture increased over time. Ruminal microorganisms from Brazilian naturalized goat and sheep breeds successfully colonized and biodegraded both WB and HB. Sodium hydroxide proved useful as an alkaline pretreatment for SCB.
\end{abstract}

KEYWORDS: Cellulolytic enzymes. Sodium hydroxide. Small ruminant. Residue.

\title{
REFERÊNCIAS
}

AOAC, Official methods of analysis, 15.ed. Association of Official Analytical Chemists, Arlington, 1990.

BRADFORD, M. M. A rapid and sensitive method for the quantification of micrograms quantities for proteins utilizing the principle of protein-dye binding. Analytical Biochemistry, San Diego, v. 72, p. 248-254, 1976. http://dx.doi.org/10.1016/0003-2697(76)90527-3

CHAUDHRY, A. S. Nutrient composition, digestion and rumen fermentation in sheep of wheat straw treated wich calcium oxide, sodium hydroxide and alkaline hydrogen peroxide. Animal Feed Science and Technology, Netherlands, v. 74, p. 315-328, 1998a. http://dx.doi.org/10.1016/S0377-8401(98)00178-3 
CHAUDHRY, A. S. In vitro and in sacco digestibility of wheat straw treated with calcium oxide and sodium hydroxide alone or with hydrogen peroxide. Animal Feed Science and Technology, Netherlands, v. 74, p. 301-313, 1998b. http://dx.doi.org/10.1016/S0377-8401(98)00177-1

CHAUDHRY, A. S. Rumen degradation in sacco in sheep of wheat straw treated with calcium oxide, sodium hydroxide and sodium hydroxide plus hydrogen peroxide. Animal Feed Science and Technology, Netherlands, v. 83, p. 313-323, 2000. http://dx.doi.org/10.1016/S0377-8401(99)00134-0

CHEN, X. L.; WANG, J. K.; WU, Y. M.; LIU, J. X. Effects of chemical treatments of rice straw on rumen fermentation characteristics, fibrolytic enzyme activities and populations of liquid- and solid-associated ruminal microbes in vitro. Animal Feed Science Technology, Netherlands, v. 141, p. 1-14, 2008.

http://dx.doi.org/10.1016/j.anifeedsci.2007.04.006

CONAB. Companhia Nacional de Abastecimento. Acompanhamento da safra brasileira : cana-de-açúcar, v.1, Safra 2014/2015, n.2, segundo levantamento, agosto/2014 - Companhia Nacional de Abastecimento. - Brasília: Conab 2014, p.1-20. http://conab.gov.br/OlalaCMS/uploads/arquivos/14_08_28_08_52_35_boletim_cana_portugues_-_2o_lev_-_201415.pdf

CUNHA, I. S.; BARRETO, C. C.; COSTA, O. Y. A.; BOMFIM, M. A.; CASTRO, A. P.; KRUGER, R. H.; QUIRINO, B. F. Bacteria and Archaea community structure in the rumen microbiome of goats (Capra hircus) from the semiarid region of Brazil. Anaerobe, Oxford, v. 17, n. 3, p. 118-124, 2011.

http://dx.doi.org/10.1016/j.anaerobe.2011.04.018

LEHNINGER, A.L. Princípios de bioquímica de Lehninger. São Paulo: Sarvier, 2011. 1273p.

LEWINSOHN, T. M.; PRADO, P. I. How Many Species Are There in Brazil? Conservation Biology, Hoboken, v. 19, n. 3, p. 619-624, 2005. http://dx.doi.org/10.1111/j.1523-1739.2005.00680.x

MOORE, K. J.; JUNG, H. G. Lignin and fiber digestion. Journal and Range Management, Tucson, v. 54, n. 4, 2001.

MEHREZ, A. Z.; ØRSKOV, E. R. A study of the artificial fibre bag tecnhique for determing the digestibility of feed in the rumen. Journal Agricultural Science, Cambridge, v. 88, n. 3. p. 645-650, 1977.

http://dx.doi.org/10.1017/S0021859600037321

McDONALD, J. A revised model for the estimation of protein degradability in the rumen. Journal Agricultural Science, Cambridge, v. 96, n. 1, p. 251-252, 1981. http://dx.doi.org/10.1017/S0021859600032081

MIRON, J.; BEN-GHEDALIA, D.; MORRISON, M. Invited Review: Adhesion mechanisms of rumen cellulolytic bacteria. Journal Dairy Science, New York, v. 84, p. 1294-1309, 2001.

http://dx.doi.org/10.3168/jds.S0022-0302(01)70159-2

ØRSKOV, E. R.; McDONALD, J. The estimation of protein degradability in the rumen fromincubation measurements weightes according to rate of passage. Journal Agricutural Science, Cambridge, v. 92, n. 2, p. 499-503, 1979. http://dx.doi.org/10.1017/S0021859600063048

PEREIRA FILHO, J. M.; VIEIRA, E. L.; SILVA, A. M. A.; CEZAR, M. F.; AMORIM, F. U. Efeito do tratamento com hidróxido de sódio sobre a fração fibrosa, digestibilidade e tanino do feno de jurema-preta. Revista Brasileira de Zootecnia, Viçosa, v. 32, n. 1, p. 70-76, 2003.

PIRES, A. J. V., REIS, R. A., CARVALHO, G. G. P.; SIQUEIRA, G. R.; BERNARDES, T. F. Bagaço de cana-de-açúcar tratado com hidróxido de sódio. Revista Brasileira de Zootecnia, Viçosa, v. 35, n. 3, p. 953 957, 2006 (supl.). 
REYES, J.; PERALTA-ZAMORA, P.; DURÁN, N. Hidrólise enzimática de casca de arroz utilizando-se celulases. Efeito de tratamentos químicos e fotoquímicos. Química Nova, São Paulo, v. 21, n. 2, p. 140-143, 1998.

RIBEIRO, L. S. O.; PIRES, A. J. V.; CARVALHO, G. G. P.; CHAGAS, D. M. T. Degradabilidade da matéria seca e da fração fibrosa da cana-de-açúcar tratada com hidróxido de sódio ou óxido de cálcio. Revista

Brasileira de Saúde e Produção Animal, Salvador, v. 10, n. 3, p. 573-585, 2009.

SALLES, H. O. GOMES, G. M. F. ANDRADE, L. B. S. ALBUQUERQUE, F. H. M. A. R. EGITO, A. S. Metodologia científica: ensaio alternativo para triagem de extratos proteicos com atividade celulolítica.

Comunicado Técnico, Sobral, 112, 2010, 4p. (Online)

SAMPAIO, I. B. M. Experimental designs and modelling techniques in the studies of roughage degradation in rumen and growth of ruminants. 1988. 228f. (PhD thesis) Univestity of Reading, Reading, 1988.

STATISTICAL ANALYSIS SYSTEMS - SAS. SAS/onleineDoc ${ }^{\circledR}$. Versão 9.2. Cary: 2009.

SUN, J. X.; SUN, X. F.; ZHAO, H.; SUN, R. C. Isolation and characterization of cellulose from sugarcane bagasse. Polymer Degradation and Stability, Oxford, v. 84, p. 331-339, 2004.

http://dx.doi.org/10.1016/j.polymdegradstab.2004.02.008

TARKOV, H.; FEIST, W. C. A mechanism for improving the digestibility of lignocelulosic materials wich dilute alkali and liquid ammonia. Advances in Chemistry Series, Washington, v. 95, n. 1, p. 197-218, 1969.

TILLEY, J. M. A.; TERRY, R. A. A two stage technique for the in vitro digestion of forage crops. Grass and Forage Science, Hoboken, v. 18, n. 2, p. 104-111, 1963. http://dx.doi.org/10.1111/j.1365-2494.1963.tb00335.x

VAN SOEST, P. J. Nutritional ecology of the ruminant, Ithaca: Cornell University Press. 1994. 476p.

VAN SOEST, P. J.; ROBERTSON, J. B.; LEWIS, B. A. Methods for dietary iber, neutral detergent iber, and nonstarch polyssacarides in relation to animal nutrition. Journal of Dairy Science, New York, v. 74, n. 10, p. 3583-3597, 1991. http://dx.doi.org/10.3168/jds.S0022-0302(91)78551-2 